\title{
Relationship between Air Pollution Index (API) and Crowd Health in Nanchang City
}

\author{
Xiaozhen Liu, Yue Liang, Daowen Yuan \\ Key Laboratory of Poyang Lake Environment and Resource Utilization, Ministry of Education, Nanchang \\ University, Nanchang, China \\ Email: liuxiaozhen@ncu.edu.cn
}

Received 9 December 2015; accepted 6 April 2016; published 11 April 2016

\begin{abstract}
Objective: To explore the effect of Air Pollution Index (API) on people's health. Methods: The data on air pollution index (API), $\mathrm{NO}_{2}, \mathrm{SO}_{2}$ and $\mathrm{PM}_{10}$ were based on the everyday monitoring information from environmental monitoring station of Nanchang City. The everyday outpatient service diseases information of $\mathbf{2 0 0 5}$ related to air pollution from some First Level Hospitals in Nanchang city was collected, and was summarized and analyzed by statistics software of Excel 2003 and SPSS11.5. Results: The average concentrations of $\mathrm{NO}_{2}, \mathrm{SO}_{2}$ and $\mathrm{PM}_{10}$ in the air of Nanchang city from 2006-2009 were $19.70 \pm 8.56 \mu \mathrm{g} / \mathrm{m}^{3}, 44.60 \pm 10.45 \mu \mathrm{g} / \mathrm{m}^{3}, 62.30 \pm 19.76 \mu \mathrm{g} / \mathrm{m}^{3} \mathrm{respectively}$. Tight relationship was detected between $\mathrm{NO}_{2}, \mathrm{SO}_{2}$ and $\mathrm{PM}_{10}$. Air pollution index (API) can better reflect the air pollution status of Nanchang city. There were positive correlations between API and number of outpatient service diseases, including cardiovascular disease, respiratory disease, ophthalmology disease and ear-nose-throat (ENT) disease in Nanchang city. Conclusion API was related to the number of outpatient service relative diseases.
\end{abstract}

\section{Keywords}

Air Pollution Index (API), Disease, Number of Outpatient Service Diseases

\section{Introduction}

Atmospheric particulate matter (PM) is a complex mixture of elemental and organic carbon, ammonium, nitrate, sulphate, mineral dust, trace elements, and water [1]. PM, esp. $\mathrm{PM}_{10}$ (particulate matter with an aerodynamic diameter smaller than $10 \mathrm{~mm}$ ) plays an important role in air pollution for its effects on human health and on the environmental behaviour [2]. It was further reported that as a main kind of pollutant, $\mathrm{PM}_{10}$ not only played an important role in climate change for its reduction of visibility [3], but also was associated with an increase of morbidity and mortality related to cancer, reproductive, respiratory and cardiovascular diseases [4].

Since the year 1999, $\mathrm{NO}_{2}$ and $\mathrm{PM}_{10}$ have been reported in Environmental Bulletin in place of NOx and TSP in major cities like Beijing of China [5]. Urban residents have been demanding to improve air quality as the Chinese Government has established air quality monitoring sites in nearly every city, providing the public with detailed information regarding air condition and daily air pollution index (API). Residents express more concerns 
about air quality in their cities [6].

Air pollution index (API) data have been extensively used in studies on air pollution in China [7] [8], based on a network of multiple monitoring stations, which represent different zones (industrial, commercial, traffic and residential) and the suburban background. Five designated pollutants: $\mathrm{PM}_{10}, \mathrm{SO}_{2}, \mathrm{NO}_{2}, \mathrm{CO}$ and $\mathrm{O}_{3}$ (in some cities three pollutants were collected: $\mathrm{PM}_{10}, \mathrm{SO}_{2}$ and $\mathrm{NO}_{2}$ ) are measured [7].

API is a simplified figure that joins the several kinds of air pollutant concentration by conventional monitoring into a single concept numerical form, and hierarchically represents air quality status and the degree of air pollution. The result of the index (API) can directly conveniently describe the air quality in a city within a designated period of time. Calculating API sub-index (sub-API) of each pollutant, the biggest sub-API of all kinds of pollutants in the pollution is the city's air pollution index of the day (API), and the corresponding pollutant with the biggest sub-API is identified as the principal pollutant for the city [7]. That is to say, every day air pollution index API of city represents the primary pollutant of that day.

In 2003, as the primary pollutant in Nanchang city, $\mathrm{PM}_{10}$ accounted for more than 80\%. In 2004 and 2005, $\mathrm{PM}_{10}$ accounted for more than $90 \%$. $\mathrm{PM}_{10}$ has become the characteristics of air pollution contaminants in Nanchang city, $\mathrm{SO}_{2}$ is in the second place [9].

More reports are based on atmospheric particulates to study the respiratory system and cardiovascular system diseases [4] [10], but the relationship research between air pollution index (API) and related disease was less than rare. In order to further discuss the air pollution characters and potential hazard in Nanchang city, the main parameters of the city air pollution and outpatient service visits of related diseases were collected and analyzed statistically.

\section{Material and Methods}

The API of 2005 and the data of $\mathrm{NO}_{2}, \mathrm{SO}_{2}$ and $\mathrm{PM}_{10}$ of 2006-2009 in the air of Nanchang city were from the daily report of Jiangxi Meteorological Bureau, the daily monitoring data provided by Environmental Monitoring Station of Nanchang City. The visit of outpatient service diseases related to air pollution in 2005 was investigated retrospectively from a First-Level hospital in Nanchang city, i.e. the daily outpatient service medical material in the whole year of 2005 was collected. At first the cases of outside Nanchang city were eliminated according to the family addresses on medical record, then the diseases related to air pollution were classified and analyzed by statistics software of Excel 2003 and SPSS11.5 based on the registered disease species, such as cardiovascular disease, respiratory disease, ophthalmology diseases, ENT diseases, dermatology diseases, etc. Relationships between API and various diseases were established, the correlation analysis of linear regression was processed, and the effect on human health from air pollution was comprehensively evaluated.

\section{Result and Analysis}

\subsection{Mutual Relations among $\mathrm{NO}_{2}, \mathrm{SO}_{2}$ and $\mathrm{PM}_{10}$ in the Air of Nanchang}

Between January 9, 2006 and October 3, 2009, the data of $\mathrm{NO}_{2}, \mathrm{SO}_{2}$ and $\mathrm{PM}_{10}$ of 361 days were collected from 9 atmospheric monitoring spots of Nanchang city. The average values of $\mathrm{NO}_{2}, \mathrm{SO}_{2}$ and $\mathrm{PM}_{10}$ were $19.70 \pm 8.56$ $\mu \mathrm{g} / \mathrm{m}^{3}, 44.60 \pm 10.45 \mu \mathrm{g} / \mathrm{m}^{3}, 62.30 \pm 19.76 \mu \mathrm{g} / \mathrm{m}^{3}$ (see Table 1), which were far lower than the concentrations of air pollution of Jinan city of China, $\mathrm{NO}_{2} 42.1 \pm 25.8 \mu \mathrm{g} / \mathrm{m}^{3}, \mathrm{SO}_{2} 59.9 \pm 61.7 \mu \mathrm{g} / \mathrm{m}^{3}, \mathrm{PM}_{10} 140.6 \pm 71.6 \mu \mathrm{g} / \mathrm{m}^{3}$, respectively [11]; there were relations among them (see Table 2). The above results indicate that the API constitutes the primary daily pollutant of the city and can well reflect the local air pollution condition of Nanchang.

\subsection{Effect on Hospital Visits of Cardiovascular Disease from API}

From January 1 to December 31 in 2005, the daily hospital visits of cardiovascular disease were 67 - 317 cases,

Table 1. Air quality monitoring results of 2006-2009 in Nanchang city (unit: $\mu \mathrm{g} / \mathrm{m}^{3}$ ).

\begin{tabular}{ccccc}
\hline Detection items & Minimum & Maximum & Mean & Standard deviation \\
\hline $\mathrm{NO}_{2}$ & 7.00 & 59.00 & 19.70 & 4.56 \\
$\mathrm{SO}_{2}$ & 22.00 & 79.00 & 44.60 & 10.45 \\
$\mathrm{PM}_{10}$ & 5.00 & 139.00 & 62.30 & 19.76
\end{tabular}


the mean of which was $144.92 \pm 37.91$ cases. API's influence on the hospital visits of cardiovascular disease and its correlation were shown in Figure 1, $F=6.174, \mathrm{R}^{2}=0.0168, \mathrm{R}=0.13, \mathrm{P}=0.013<0.05$, the relationship between API and hospital visits of cardiovascular disease was closely related (positive correlation). These results are similar to those observed in other studies [12] [13], which showed the effect of ambient air pollution on hospital admissions of circulatory system diseases and daily cardiovascular mortality.

\subsection{Effect on Hospital Visits of Respiratory Disease from API}

Between January 1, 2005 and December 31, 2005, the daily hospital visits of respiratory disease were 0 - 279 cases, and the mean was $77.02 \pm 38.21$ cases. API's influence on the hospital visits of respiratory disease and its correlation showed in Figure 2, F $=4.247, \mathrm{R} 2=0.0116, \mathrm{R}=0.11, \mathrm{P}=0.040<0.05$, API was closely related to hospital visits of respiratory disease (positive correlation), which was consistent to the research result of Wang Yan [11], showing the effect of air pollution on the daily hospital visits of respiratory disease.

Table 2. Relationship among $\mathrm{NO}_{2}, \mathrm{SO}_{2}, \mathrm{PM}_{10}$.

\begin{tabular}{ccccc}
\hline Items & Regression equation & $\mathrm{R}^{2}$ & $\mathrm{~F}$ & $\mathrm{P}$ \\
\hline $\mathrm{NO}_{2}, \mathrm{SO}_{2}$ & $\mathrm{Y}=0.8317 \mathrm{x}+28.2260$ & 0.466 & 308.164 & $<0.01$ \\
$\mathrm{SO}_{2}, \mathrm{PM}_{10}$ & $\mathrm{Y}=1.2236 \mathrm{x}+7.7476$ & 0.419 & 256.860 & $<0.01$ \\
$\mathrm{NO}_{2}, \mathrm{PM}_{10}$ & $\mathrm{Y}=1.3234 \mathrm{x}+36.2690$ & 0.330 & 174.297 & $<0.01$ \\
\hline
\end{tabular}

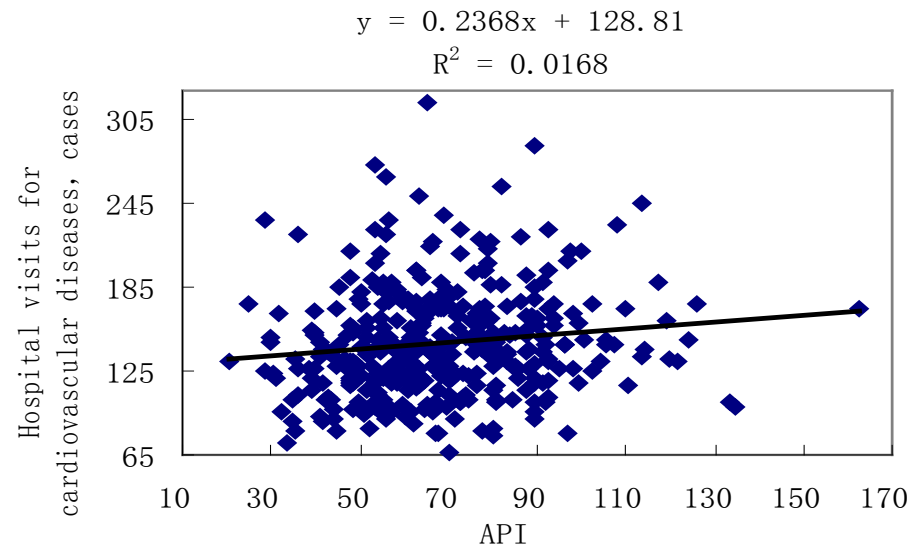

Figure 1. Relationship between API and hospital visits for cardiovascular diseases.

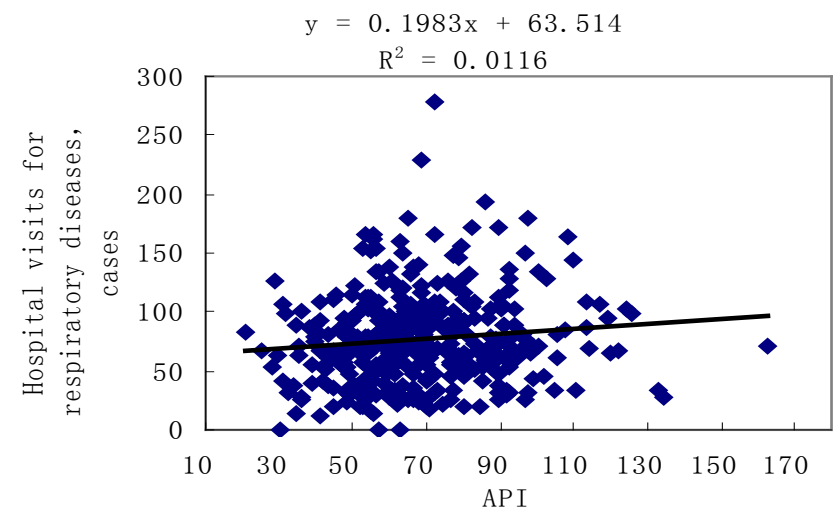

Figure 2. Relationship between API and hospital visits for respiratory diseases. 


\subsection{Effect on Hospital Visits of Ophthalmology Disease from API}

Between January 1, 2005 and December 31, 2005, the daily hospital visits of ophthalmology disease were 10 282 cases, the mean was $124.38 \pm 51.20$ cases. API’s influence on the hospital visits of ophthalmology disease and its correlation showed in Figure 3, $\mathrm{F}=5.145, \mathrm{R}^{2}=0.0141, \mathrm{R}=0.12, \mathrm{P}=0.024<0.05$, API was positively correlated to hospital visits of ophthalmology disease.

\subsection{Effect on Hospital Visits of ENT Disease from API}

Between January 1, 2005 and December 31, 2005, the daily hospital visits of ENT disease were 13 - 343 cases, and the mean was $169.15 \pm 67.10$ cases. API's influence on the hospital visits of ENT disease and its correlation was shown in Figure 4, $\mathrm{F}=4.362, \mathrm{R}^{2}=0.0121, \mathrm{R}=0.11, \mathrm{P}=0.037<0.05$, API was positively correlated to hospital visits of ENT (ear-nose-throat) disease.

\subsection{Effect on Hospital Visits of Dermatology Disease from API}

Between January 1, 2005 and December 31, 2005, the daily hospital visits of dermatology disease were 0 - 202 cases, and the mean was $99.94 \pm 40.15$ cases. API's influence on the hospital visits of dermatology disease and its correlation was shown in Figure 5, $\mathrm{F}=2.055, \mathrm{R}^{2}=0.0058, \mathrm{R}=0.076, \mathrm{P}=0.153>0.05$, and the relationship between API and the hospital visits of dermatology disease was not evident.

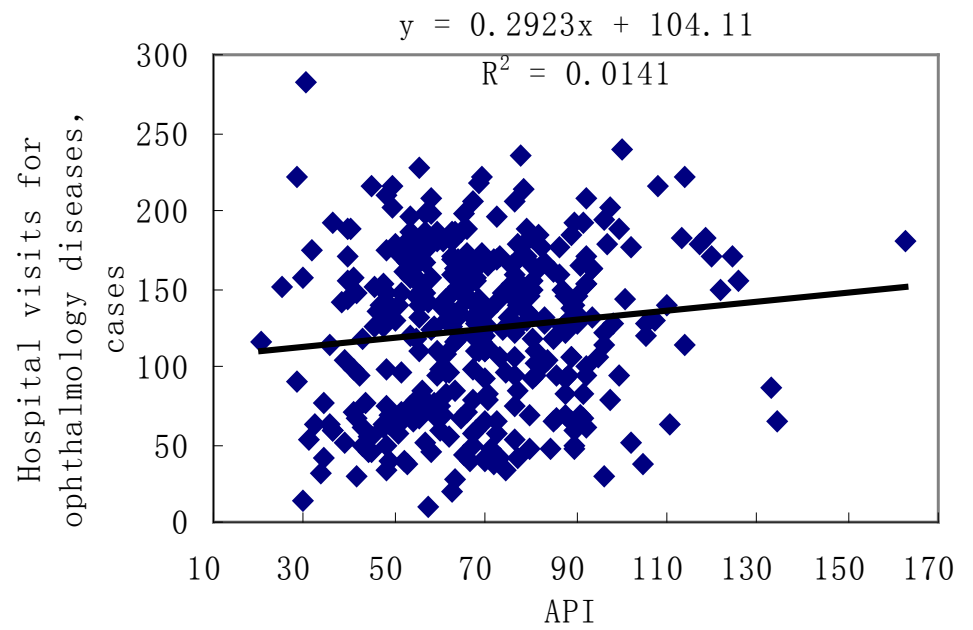

Figure 3. Relationship between API and hospital visits for ophthalmology diseases.

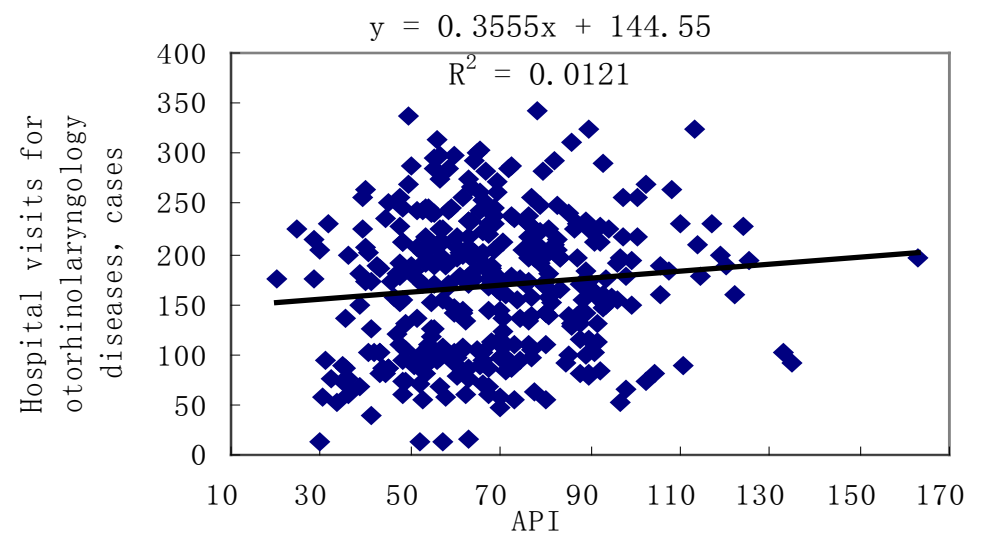

Figure 4. Relationship between API and hospital visits for otorhinolaryngology diseases. 


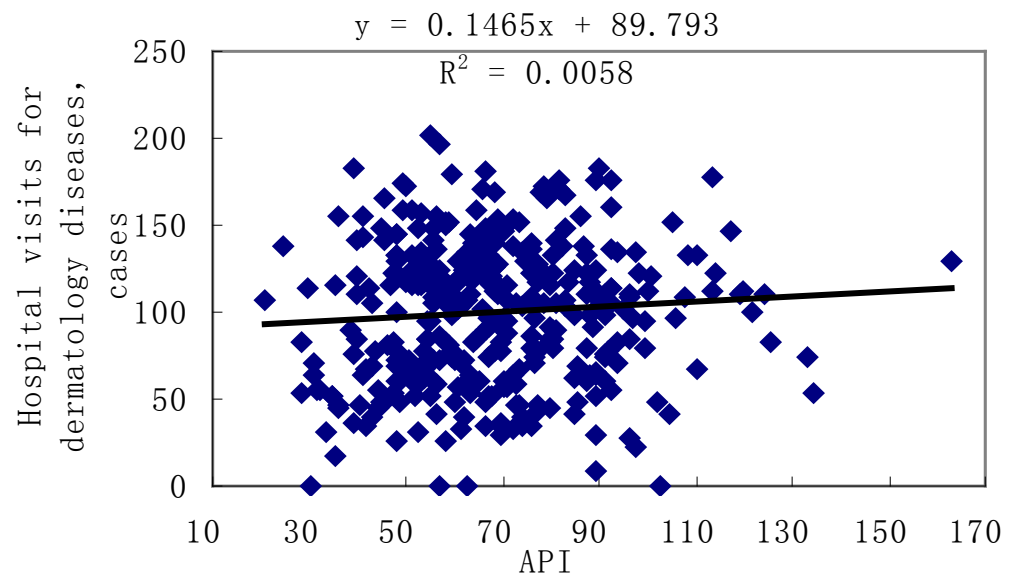

Figure 5. Relationship between API and hospital visits for dermatology diseases.

\section{Conclusions}

The average concentrations of $\mathrm{NO}_{2}, \mathrm{SO}_{2}, \mathrm{PM}_{10}$ from 2006-2009 were $19.70 \pm 8.56 \mu \mathrm{g} / \mathrm{m}^{3}, 44.60 \pm 10.45 \mu \mathrm{g} / \mathrm{m}^{3}$, $62.30 \pm 19.76 \mu \mathrm{g} / \mathrm{m}^{3}$. There were closely relations among $\mathrm{NO}_{2}, \mathrm{SO}_{2}$ and $\mathrm{PM}_{10}$. The urban air pollution index (API) with daily primary pollutants as the foundation can well reflect the local air pollution condition.

The API of Nanchang city is closely related to the daily hospital visits of cardiovascular diseases, respiratory diseases, eye diseases and ENT diseases (positive correlation), but not related to the hospital visits of dermatology disease. The above research about the relationship between API and hospital visits of related diseases, such as cardiovascular diseases, respiratory diseases, eye diseases, ENT diseases and dermatology diseases, has not been reported before, so further in-depth study esp. about $\mathrm{Pb}$ pollution of $\mathrm{PM}_{2.5}$ in the industry area and traffic lines will be necessary.

\section{Acknowledgements}

This study was supported by Jiangxi Provincial Health Bureau of P. R. China grant NO: 20122018, and Nanchang City Scientific Technology Bureau of P. R. China grant NO: 2014-CXYHZ-ZYHJ-001 (Area distribution characteristics of $\mathrm{PM}_{2.5}$ pollution and its related influencing factors analysis and the prevention \& control measures in Nanchang City), and Jiangxi Provincial Research Center of Industry Safety Engineering Technology of P. R. China grant NO: 2013GGY003.

\section{References}

[1] Hueglina, C., Gehriga, R., Baltensperger, U., Gysel, M., Monnd, C., Vonmont, H. (2005) Chemical Characterisation of PM2.5, PM10 and Coarse Particles at Urban, Near-City and Rural Sites in Switzerland. Atmospheric Environment, 39, 637-651. http://dx.doi.org/10.1016/j.atmosenv.2004.10.027

[2] Gehrig, R. and Buchmann, B. (2003) Characterising Seasonal Variations and Spatial Distribution of Ambient PM10 and PM2.5 Concentrations Based on Long-Term Swiss Monitoring Data. Atmospheric Environment, 37, 2571-2580. http://dx.doi.org/10.1016/S1352-2310(03)00221-8

[3] Liu, X.Z. and Smith, S. (2006) Effect of Trajectory Wind Direction on Ion Concentration of PM10. Biomedical and Environmental Sciences, 19, 262-267.

[4] Mills, N.L., Donaldson, K. and Hadoke, P.W. (2009) Adverse Cardiovascular Effects of Air Pollution. Nat Clin Pract Cardiovasc Med, 6, 36-44. http://dx.doi.org/10.1038/ncpcardio1399

[5] Chan, C.K. and Yao, X.H. (2008) Air Pollution in Mega Cities in China. Atmospheric Environment, 42, 1-42. http://dx.doi.org/10.1016/j.atmosenv.2007.09.003

[6] Wang, Y. and Zhang, Y.-S. (2009) Air Quality Assessment by Contingent Valuation in Ji'nan, China. Journal of Environmental Management, 90, 1022-1029. http://dx.doi.org/10.1016/j.jenvman.2008.03.011

[7] Li, C., Christina, H.N. and Tsay, S.-C. (2011) A Study on the Potential Applications of Satellite Data in Air Quality Monitoring and Forecasting. Atmospheric Environment, 45, 3663-3675. http://dx.doi.org/10.1016/j.atmosenv.2011.04.032 
[8] Gao, H.W., Chen, J., Wang, B., Tan, S.-C., Lee, C.M., Yao, X.H., Yan, H. and Shi, J.H. (2011) A Study of Air Pollution of City Clusters. Atmospheric Environment, 45, 3069-3077. http://dx.doi.org/10.1016/j.atmosenv.2011.03.018

[9] Jin, J., Liu, X.-Z., Zhang, W.-P. and Lin, P.-D. (2006) Status Quo of Air Quality in Urban Area of Nanchang City. Jiangxi Science, 24, 522-524.

[10] Dominici, F., McDermott, A. and Daniels, M. (2005) Revised Analyses of the National Morbidity, Mortality, and Air Pollution Study: Mortality among Residents of 90 Cities. J Toxicol Environ Health A, 68, 1071-1092. http://dx.doi.org/10.1080/15287390590935932

[11] Wang, Y., Zhang, Y.-S. and Li, X.-P. (2008) The Effect of air Pollution on Hospital Visits for Respiratory Symptoms in Urban Areas of Jinan. China Environment Science, 28, 571-576.

[12] Yan, J.,Wang, Z.-Q. and Lian, S.-Q. (2010) Impact of Ambient Air Pollution on Daily Circulatory System Disease Hospitalization in Lanzhou City. Chinese Journal of Public health, 26, 1514-1516.

[13] Yang, M.-J. and Pan, X.-C. (2008) Time-Series Analysis of Air Pollution and Cardiovascular Mortality in Beijing, China. Journal of Environment and Health, 25, 294-297. 